\title{
Glutaminyl Cyclase in Human Cortex: Correlation with (pGlu)-Amyloid- $\beta$ Load and Cognitive Decline in Alzheimer's Disease
}

\author{
Markus Morawski ${ }^{\mathrm{a}, 1}$, Stephan Schilling ${ }^{\mathrm{b}, 1}$, Moritz Kreuzberger ${ }^{\mathrm{a}, 1}$, Alexander Waniek ${ }^{\mathrm{a}}$, Carsten Jäger ${ }^{\mathrm{a}}$, \\ Birgit Koch $^{\mathrm{b}}$, Holger Cynis ${ }^{\mathrm{b}, \mathrm{c}}$, Astrid Kehlen ${ }^{\mathrm{b}}$, Thomas Arendt ${ }^{\mathrm{a}}$, Maike Hartlage-Rübsamen ${ }^{\mathrm{a}}$, \\ Hans-Ulrich Demuth ${ }^{\mathrm{b}, *}$ and Steffen Roßner ${ }^{\mathrm{a}, *}$ \\ ${ }^{a}$ Paul Flechsig Institute for Brain Research, University of Leipzig, Leipzig, Germany \\ ${ }^{\mathrm{b}}$ Probiodrug AG, Halle/S., Germany \\ ${ }^{\mathrm{c} C e n t e r}$ for Neurologic Disease, Brigham and Women's Hospital, Harvard Medical School, Boston, MA, USA
}

Handling Associate Editor: Stefan Lichtenthaler

Accepted 17 September 2013

\begin{abstract}
Brains of Alzheimer's disease (AD) patients are characterized in part by the formation of high molecular weight aggregates of amyloid- $\beta(\mathrm{A} \beta)$ peptides, which interfere with neuronal function and provoke neuronal cell death. The pyroglutamate (pGlu) modification of $\mathrm{A} \beta$ was demonstrated to be catalyzed by the enzyme glutaminyl cyclase (QC) and to enhance pathogenicity and neurotoxicity. Here, we addressed the role of QC in AD pathogenesis in human cortex. Two sets of human postmortem brain tissue from a total of 13 non-demented controls and $11 \mathrm{AD}$ cases were analyzed by immunohistochemistry and unbiased stereology, quantitative RT-PCR, and enzymatic activity assays for the expression level of QC in temporal and entorhinal cortex. Additionally, cortical $\mathrm{A} \beta$ and pGlu-A $\beta$ concentrations were quantified by ELISA. Data on QC expression and $\mathrm{A} \beta$ peptide concentrations were correlated with each other and with the Mini-Mental State Examination (MMSE) of individual cases. In control cases, QC expression was higher in the more vulnerable entorhinal cortex than in temporal cortex. In AD brains, QC mRNA expression and the immunoreactivity of QC were increased in both cortical regions and frequently associated with pGlu-A $\beta$ deposits. The analyses of individual cases revealed significant correlations between QC mRNA levels and the concentration of insoluble pGlu-A $\beta$ aggregates, but not of unmodified $A \beta$ peptides. Elevated pGlu-A $\beta$ load showed a better correlation with the decline in MMSE than elevated concentration of unmodified A $\beta$. Our observations provide evidence for an involvement of $\mathrm{QC}$ in $\mathrm{AD}$ pathogenesis and cognitive decline by $\mathrm{QC}$-catalyzed $\mathrm{pGlu}-\mathrm{A} \beta$ formation.
\end{abstract}

Keywords: Alzheimer's disease, entorhinal cortex, glutaminyl cyclase, pyroglutamate-A $\beta$, Mini-Mental State Examination

\footnotetext{
${ }^{1}$ These authors contributed equally to this manuscript.

*Correspondence to: Steffen Roßner, PhD, Paul Flechsig Institute for Brain Research, Jahnallee 59, 04109 Leipzig, Germany. Tel.: +49 341 9725758; Fax: +49 341 9725749; E-mail: steffen.rossner@medizin.uni-leipzig.de; Hans-Ulrich Demuth, Fraunhofer Institute of Cell Therapy and Immunology (IZI), Leipzig c/o, Department of Drug Design and Target Validation (MWT), Halle Biocenter, Weinbergweg, 2206120 Halle (Saale), Germany. Tel: +49 345 13142800; Fax: +49 345 13142801; E-mail: hans-ulrich.demuth@izi.fraunhofer.de.
}

\section{INTRODUCTION}

At early stages of Alzheimer's disease (AD), patients display mild disturbances in spatial and temporal orientation and in short-term memory. The relation between the actual clinical status of the patient and the degree of neuropathology can be assessed by testing cognitive function and by imaging techniques monitoring hippocampal shrinkage, $A \beta$ deposition, and microglial activation [1-3]. However, the definite diagnosis of $\mathrm{AD}$ is only possible in postmortem brain 
tissue by the detection of neurofibrillary tangles and $\mathrm{A} \beta$ deposits in cortical brain tissue [4-6].

$\mathrm{A} \beta$ peptides are generated by proteolytic processing of the amyloid- $\beta$ protein precursor $(\mathrm{A} \beta \mathrm{PP})$ by $\beta$ and $\gamma$-secretases [7]. A substantial proportion of $A \beta$ peptides undergoes N-terminal truncation and subsequent cyclization of $\mathrm{N}$-terminal glutamate (Glu) into pyroglutamate (pGlu), resulting in pGlu-A $\beta$ peptides [8-11]. Such pGlu-A $\beta$ peptides are major constituents of $\mathrm{A} \beta$ deposits in sporadic and familial $\mathrm{AD}[8,12-14]$ and, based on a number of observations, could play a prominent role in $\mathrm{AD}$ pathogenesis. For example, the pGlu modification results in accelerated aggregation $[15,16]$ and in co-aggregation of non-modified $A \beta$ peptides [17-20]. Furthermore, the pGlu residue confers resistance to degradation by most aminopeptidases as well as $\mathrm{A} \beta$-degrading endopeptidases [21]. Finally, a strong neurotoxic effect of $\mathrm{pGlu}-\mathrm{A} \beta$ peptides on primary neurons, neuronal cell lines, and neurons of A $\beta P P$ transgenic animals in vivo has been described $[16,22,23]$ and was demonstrated to be transmitted in a prion-like manner [24]. Interestingly, pGlu-modified $\mathrm{A} \beta$ peptides in brains of $\mathrm{AD}$ patients and transgenic mouse models were reported to be closely associated with $\left[{ }^{11} \mathrm{C}\right]$ Pittsburgh Compound-B (PIB) autoradiographic signals [25].

The $\mathrm{pGlu}-\mathrm{A} \beta$ peptide modification has been demonstrated to be catalyzed by glutaminyl cyclase (QC) in vitro [26] and in vivo [27-30]. In mammalian brain, physiologically relevant neuronal QC expression has been described in the hypothalamus and was shown to be involved in neuropeptide and hormone maturation [31-34]. Recently, we observed robust QC expression in mouse and human brain in AD-vulnerable subcortical regions, such as nucleus basalis Meynert, locus coeruleus, and Edinger-Westphal nucleus [35]. Moreover, we demonstrated pronounced QC immunoreactivity in a subpopulation of neocortical neurons and of GABAergic interneurons in the mouse hippocampus [36]. In the hippocampal formation of $\mathrm{AD}$ patients, distinct types of pGlu-A $\beta$ deposits were identified at sites of QC immunoreactive neurons and in target fields of QC-rich projection neurons [37]. Chronic pharmacological inhibition [29] or genetic ablation [38, 39] of QC in transgenic mouse and Drosophila models of AD resulted in reduced pGlu$\mathrm{A} \beta$ peptide generation and improved performance in cognitive tasks, while QC overexpression aggravated neuropathology and cognitive dysfunction in transgenic mice [39].

Thus, there is accumulating evidence from biochemical and histological analyses in experimental animals for a critical role of QC in pGlu-A $\beta$ formation. Such pGlu-A $\beta$ peptides provoke protein aggregation and deposition, neurodegeneration, gliosis, and impairment of learning and memory in transgenic mouse models. However, in human cortex, QC expression and its relation to $\mathrm{pGlu}-\mathrm{A} \beta$ formation have not yet been thoroughly analyzed. Moreover, no information is available on the relation between QC expression, pGlu-A $\beta$ formation, and the cognitive status of elderly humans. Here, we report a remarkably high expression of QC by neurons in temporal and entorhinal cortex of non-demented human subjects and an increase in QC immunoreactivity in both cortical areas in AD. Additionally, and for the first time, we provide evidence for a role of $\mathrm{QC}$ in the generation of pGlu-A $\beta$ in human cortex and for a relation between QC expression, pGlu-A $\beta$ formation, and cognitive decline in $\mathrm{AD}$.

\section{MATERIALS AND METHODS}

\section{Human brain tissue}

\section{Case recruitment and characterization of human brain tissue}

Case recruitment and autopsy were performed in accordance with guidelines effective at the Banner Sun Health Research Institute Brain Donation Program of Sun City, Arizona [40]. The required consent was obtained for all cases. The definite diagnosis of $\mathrm{AD}$ for all cases used in this study was based on the presence of neurofibrillary tangles and neuritic plaques in the hippocampal formation and neocortical areas and met the criteria of the National Institute on Aging (NIA) and the Consortium to establish a registry for $\mathrm{AD}$ (CERAD) [5]. Brain tissue of temporal cortex (Area 22) and entorhinal cortex (Area 28) from 6 controls and 6 age-matched $\mathrm{AD}$ cases was used for $\mathrm{QC}$ and $\mathrm{pGlu}-\mathrm{A} \beta$ immunohistochemistry. Additionally, for biochemical analyses, temporal cortex (Area 22) of 7 control cases and $5 \mathrm{AD}$ cases with a very short postmortem interval of 1.5 to 5.5 hours and a thorough clinical characterization was used (Table 1). The cases enrolled in this study were matched for age, gender, and APOE genotype. Anatomical structures and cortical layers were identified using consecutive Nissl-stained sections and the Atlas of the Human Brain [41].

\section{Tissue preparation}

For immunohistochemistry, fifteen-mm-thick tissue blocks were prepared in the frontal plane according to the Atlas of the Human Brain [41] and fixed in $4 \%$ 


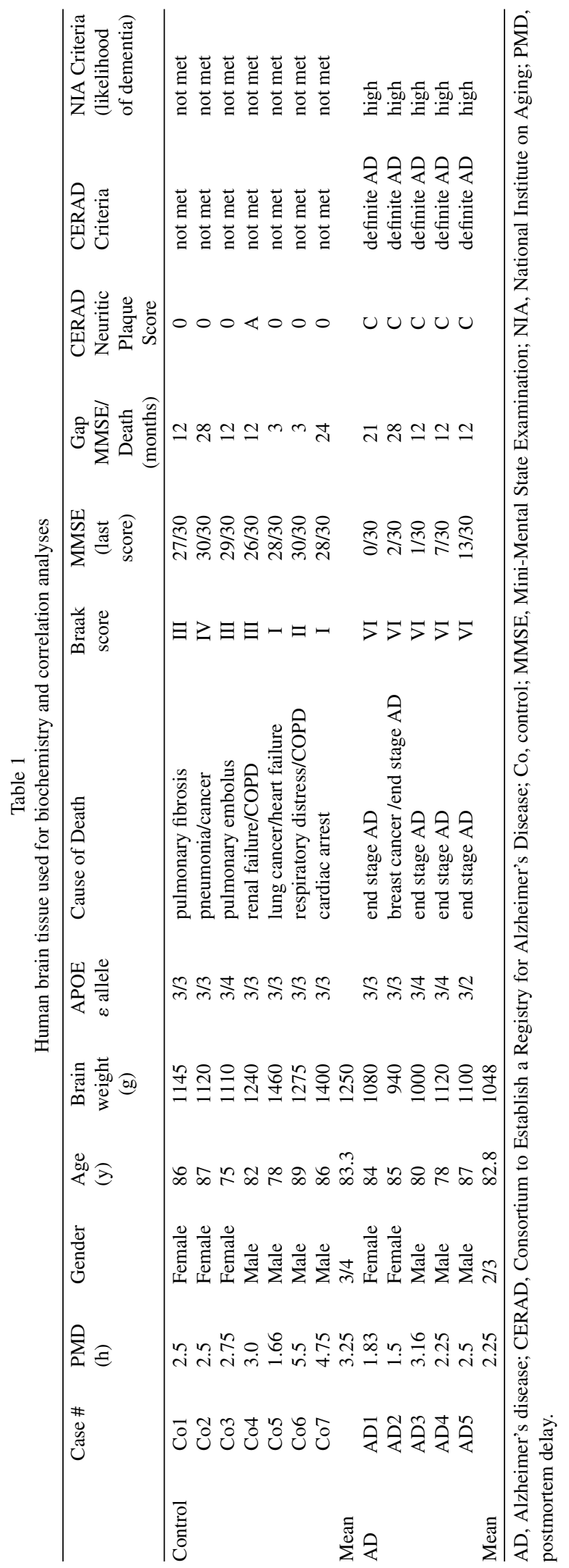


paraformaldehyde in $0.1 \mathrm{M}$ phosphate-buffered saline (PBS), $\mathrm{pH} 7.4$ for 3-4 days. Areas containing the regions of interest were cryoprotected in $30 \%$ sucrose in 0.1 M PBS, pH 7.4. Series of $30 \mu \mathrm{m}$-thick sections were cut on a freezing microtome and collected in PBS containing $0.1 \%$ sodium azide.

For biochemical analyses including A $\beta$ ELISAs, QC enzymatic activity assays and quantitative RT-PCR to detect QC transcripts, unfixed temporal cortex tissue with a short postmortem interval was stored at $-80^{\circ} \mathrm{C}$ (see Table 1). Brain tissue (10\% w/v) was homogenized in TBS (20 mM Tris, $137 \mathrm{mM} \mathrm{NaCl}, \mathrm{pH} 7.6$ ) containing protease inhibitor cocktail (Complete Mini, Roche), sonicated and aliquots of homogenates were used for QC enzymatic activity assays. Homogenates were then centrifuged at $75,500 \times g$ for 1 hour at $4{ }^{\circ} \mathrm{C}$ and the supernatant was stored at $-80^{\circ} \mathrm{C}$. $\mathrm{A} \beta$ peptides were sequentially extracted with TBS/1\% Triton X-100 (TBS/triton fraction), 2\% sodium dodecylsulfate (SDS) in distilled water (SDS fraction), and 70\% formic acid (FA fraction). The combined SDS and FA fractions were considered as the insoluble pool of $A \beta$.

\section{$Q C$ and $p G l u-A \beta$ antibodies}

Since the specificity of the immunohistochemical QC labeling is critical for this study, we tested four different QC antibodies; 1301 (rabbit anti-QC) and 10269 (goat anti-QC) developed by Probiodrug (Halle, Germany) and the mouse anti-QC antibodies A01 and B01 from Abnova (Heidelberg, Germany). All four antibodies from three different species generated similar staining patterns with a robust cytosolic labeling of layer III pyramidal neurons, indicating specific detection of QC (Fig. 1). Based on the superior signal to background ratio, the mouse anti-QC antibody A01 was selected for the analyses of QC expression in human cortex.

pGlu-A $\beta$ peptides in cortex of $A D$ cases were detected using the mouse monoclonal antibody mab248 (Synaptic Systems; Göttingen, Germany), which has been thoroughly characterized by Wirths et al. [42]. This antibody specifically detects the pGlu-A $\beta$ neo-epitope generated by QC activity and does not cross-react with mouse $A \beta$ nor with human $A \beta_{1-40 / 42}$ or $N$-truncated human $A \beta_{3-40 / 42}$ lacking the pGlu modification. When required for double labeling procedures (see below), a rabbit anti-pGlu-A $\beta$ antiserum (Synaptic Systems) was used. The rabbit anti-pGlu-A $\beta$ and mouse anti-pGlu-A $\beta$ antibodies showed an identical staining pattern of human brain tissue (not shown).

\section{Immunohistochemistry for human brain tissue}

\section{Nissl staining}

Coronal sections of the human hippocampus were mounted on gelatin-coated slides and stained in $0.1 \%$ cresyl violet according to standard protocols.

\section{Single labeling QC immunohistochemistry}

All immunohistochemical procedures were performed on free-floating brain sections. Immunohistochemistry to detect QC in human brain was performed using the mouse anti-QC antiserum A01 (Abnova; $1: 2,000)$. All sections were pre-treated with an initial antigen retrieval step by heating to $90^{\circ} \mathrm{C}$ in $0.1 \mathrm{M}$ citrate buffer, $\mathrm{pH} 2.5$, for 3 minutes followed by rinsing with PBS; pH 7.4 containing $0.05 \%$ Tween (PBS-T). Brain sections were further treated with $2 \% \mathrm{H}_{2} \mathrm{O}_{2}$ in $60 \%$ methanol for 1 hour, to abolish endogenous peroxidase activity. Unspecific staining was blocked in PBS-T containing $2 \%$ bovine serum albumin (BSA), $0.3 \%$ milk powder, and $0.5 \%$ normal donkey serum before incubating brain sections with the primary anti-QC antibody at $4{ }^{\circ} \mathrm{C}$ overnight. The following day sections were incubated with secondary biotinylated donkey anti-mouse antibodies (Dianova; 1:1,000) for 60 minutes at room temperature followed by the $\mathrm{ABC}$ method which comprised incubation with complexed streptavidin-biotinylated horseradish peroxidase. Incubations were separated by washing steps (3-times 5 minutes in PBS-T). Binding of peroxidase was visualized by incubation with $2 \mathrm{mg}$ 3,3'-diaminobenzidine (DAB), $20 \mathrm{mg}$ nickel ammonium sulfate, and $2.5 \mu \mathrm{l} \mathrm{H}_{2} \mathrm{O}_{2}$ per $5 \mathrm{ml}$ Tris buffer (0.05 M; pH 8.0) for 1-2 minutes, resulting in black labeling.

Sections from control and AD cases were processed in parallel with the same washing, antibody, and staining solutions for the same period of time to prevent technical staining differences.

\section{Double labeling immunohistochemistry}

Simultaneous immunohistochemical labeling of QC and pGlu-A $\beta$ was performed using mouse anti-QC (A01, 1:2,000; Abnova) and rabbit anti-pGlu-A $\beta$ (Synaptic Systems; 1:500) antibodies. As for single labeling, all sections were pre-treated with $2 \%$ $\mathrm{H}_{2} \mathrm{O}_{2}$ in $60 \%$ methanol for 60 minutes and unspecific staining was blocked by treatment with PBS-T containing $2 \%$ BSA, $0.3 \%$ milk powder, and $0.5 \%$ normal donkey serum before incubating brain sections with the primary antibodies in blocking solution at $4^{\circ} \mathrm{C}$ for 24 hours. Thereafter, the tissue was transferred 
to a mixture of blocking solution and PBS-T buffer (1:2) containing secondary biotinylated donkey anti-mouse antibody (Dianova; 1:400) followed by incubation with extravidin-conjugated peroxidase (Sigma-Aldrich, Germany; 1:2,000) in blocking solution and PBS-T buffer (1:3) for 60 minutes at room temperature. Binding of peroxidase was visualized in a solution containing $4 \mathrm{mg} \mathrm{DAB}, 40 \mathrm{mg}$ ammonium nickel(II)-sulfate, and $5 \mu l \mathrm{H}_{2} \mathrm{O}_{2}$ per $10 \mathrm{ml}$ Tris-buffer (0.05 M; pH 8.0) yielding black epitope staining. Bound peroxidase was then inactivated with $2 \% \mathrm{H}_{2} \mathrm{O}_{2}$ in $60 \%$ methanol (15 minutes) to allow subsequent detection of pGlu-A $\beta$ with a peroxidase-labeled donkey anti-rabbit antibody (Dianova; 1:200; 60 minutes) followed by visualization of second round peroxidase binding with $2 \mathrm{mg}$ DAB and $2.5 \mu \mathrm{H} \mathrm{H}_{2} \mathrm{O}_{2}$ per $5 \mathrm{ml}$ Tris buffer $(0.05 \mathrm{M} ; \mathrm{pH} 7.6)$ resulting in a brown precipitate.

\section{Quantification of QC-immunoreactive neurons}

Quantitative analysis of QC-immunoreactive neurons present in temporal and entorhinal cortex was performed. Neurons were counted when a minimum soma diameter of $8 \mu \mathrm{m}$ and at least one dendrite could be identified. The location of neurons throughout all cortical layers from the cortical surface to the white matter boundary was assessed by means of the optical fractionator method. In the present investigation, the number of QC-positive neurons was counted in discrete neocortical areas of temporal cortex (area 22) and entorhinal cortex (area 28) of six control brains and six cases with a neuropathologically-confirmed diagnosis of AD. Counts were performed on a Zeiss Axioskop 2 plus microscope equipped with a motorized stage, a Ludl MAC 5000 (LEP, Hawthorne, NY, USA) and a digital camera 9000 (MicroBrightField, Williston, VT, USA). Stereo Investigator software 7 (MicroBrightfield) was used to analyze frontal sections (nominal thickness of $30 \mu \mathrm{m}$ ) of selected areas. Each section was first viewed at low magnification $(5 \times)$ for outlining the relevant parts of cortical areas, and disector frames were placed in a systematic-consecutive fashion in the delineated regions of the sections. Neurons that fell within these disector frames $(250 \mu \mathrm{m} \times 1000 \mu \mathrm{m})$ were then counted at high magnification $(10 \times)$. On average, the post-processing shrinkage of the tissues resulted in a final section thickness of about $16 \mu \mathrm{m}$, which permitted a consistent sampling of $10 \mu \mathrm{m}$ with the dissector and the use of guard zones of $2 \mu \mathrm{m}$ on either sides of the section. Three sections per case and area investigated were used. The number of QCpositive neurons was converted to numerical density per $\mathrm{mm}^{2}$ and is given as mean $\pm \mathrm{SD}$ of 6 control and 6 AD cases.

Cells were considered to be immunoreactive when they were clearly visible at the settings: brightness -0.5 ; contrast 2.5; and gamma 1.6. Neurons were assigned to the strongly QC-immunoreactive group, when the soma was clearly above background at the threshold settings brightness 2.0; contrast 10.0; and gamma 3.0. In consecutive brain sections, the total number of neurons was calculated by Nissl staining and was set to represent $100 \%$ of neurons. The relative numbers of QC-immunoreactive neurons in brain regions analyzed was calculated using the formula of Konigsmark [43].

\section{$q R T-P C R$ for $Q C$}

Tissue samples were homogenized by means of the homogenizer Precellys with $1.4 \mathrm{~mm}$ ceramic beads (5000 rpm, 30 seconds, Peqlab). RNA was isolated using the NucleoSpin RNA II kit (Macherey Nagel) according to the manufacturer's instructions. The quality of isolated RNA was validated by calculating the ratio of absorbance at 260 and $280 \mathrm{~nm}$, which was consistently above 2 . RNA concentrations were measured using a NanoDrop 2000 spectrophotometer (Peqlab) and $0.1 \mu \mathrm{g}$ RNA was reverse transcribed into cDNA using random primers (Roche) and Superscript III (Life technologies). Quantitative PCR was performed in a Rotorgene3000 (Corbett Research) using the RotorGene SYBR Green PCR kit and the Quantitect primer assays HsQPCT (Qiagen). Relative amounts of gene expression were determined with the Rotorgene software version 6.1 in comparative quantitation mode. Normalization was done against the stably expressed reference gene YWHAZ identified using Normfinder [44]. The PCR was verified by product melting curves and single amplicons were confirmed by agarose gel electrophoresis.

\section{QC enzymatic activity assays}

QC activity was measured by a discontinuous HPLC-method using the substrate H-Gln- $\beta N A$ as described previously [27]. Briefly, QC-containing tissue lysate was incubated with substrate H-Gln- $\beta$ NA. Test samples were taken at defined time points and the reaction was stopped by boiling for 5 minutes. Analysis of pGlu- $\beta$ NA formation was done using RP18 LiChroCART HPLC Cartridge and the HPLC-system D-7000 (Merck-Hitachi). QC activity was quantified from a standard curve of pGlu- $\beta$ NA under assay conditions. 

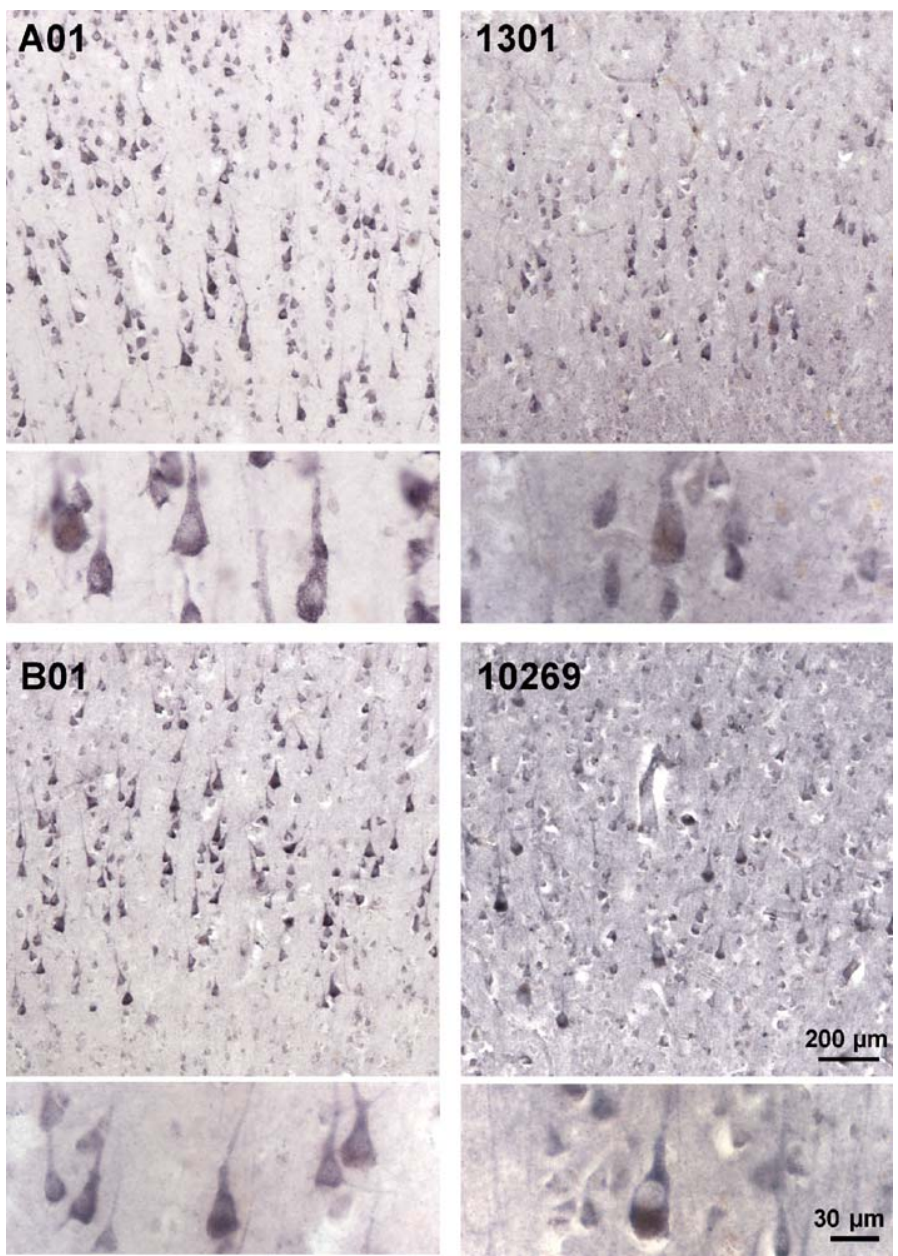

Fig. 1. Characterization of QC antibodies. Immunohistochemical detection of neurons in consecutive brain sections of Area 22 of a human control case using four different anti-QC antibodies as indicated. All antibodies primarily detect QC in the cytosol and in neurites; in particular in strongly immunoreactive pyramidal neurons in layer III. The $200 \mu \mathrm{m}$ scale bar applies to all low magnification images; the $30 \mu \mathrm{m}$ scale bar applies to all high magnification images.

\section{A $\beta$ ELISAs}

Specific ELISAs to detect $A \beta_{x-42}$ and pGlu-A $\beta_{3-42}$ (IBL, Hamburg) were performed according to the manufacturer's manual as described by Schilling et al. [29]. All samples were analyzed in triplicate and the concentrations of the respective $A \beta$ peptides present in temporal cortex were calculated from a standard curve.

\section{Statistical analyses}

Data on the number of QC-immunoreactive neurons in temporal and entorhinal cortex are the mean value of 6 control and 6 AD cases \pm SD. For biochemical measurements and correlation analyses brain tissue from 7 control and $5 \mathrm{AD}$ cases was used.
The ELISA data have been evaluated applying nonparametric Mann-Whitney tests.

\section{RESULTS}

Characterization of QC antibodies in human cortex

In order to determine the specificity of the immunohistochemical QC labeling in human cortex, four different QC antibodies raised in three species were characterized. All antibodies labeled a significant proportion of neocortical neurons with the most robust staining intensity in layer III pyramidal neurons (Fig. 1). At higher magnification, a localization of QC immunoreactivity in cytoplasm and dendrites was 
A
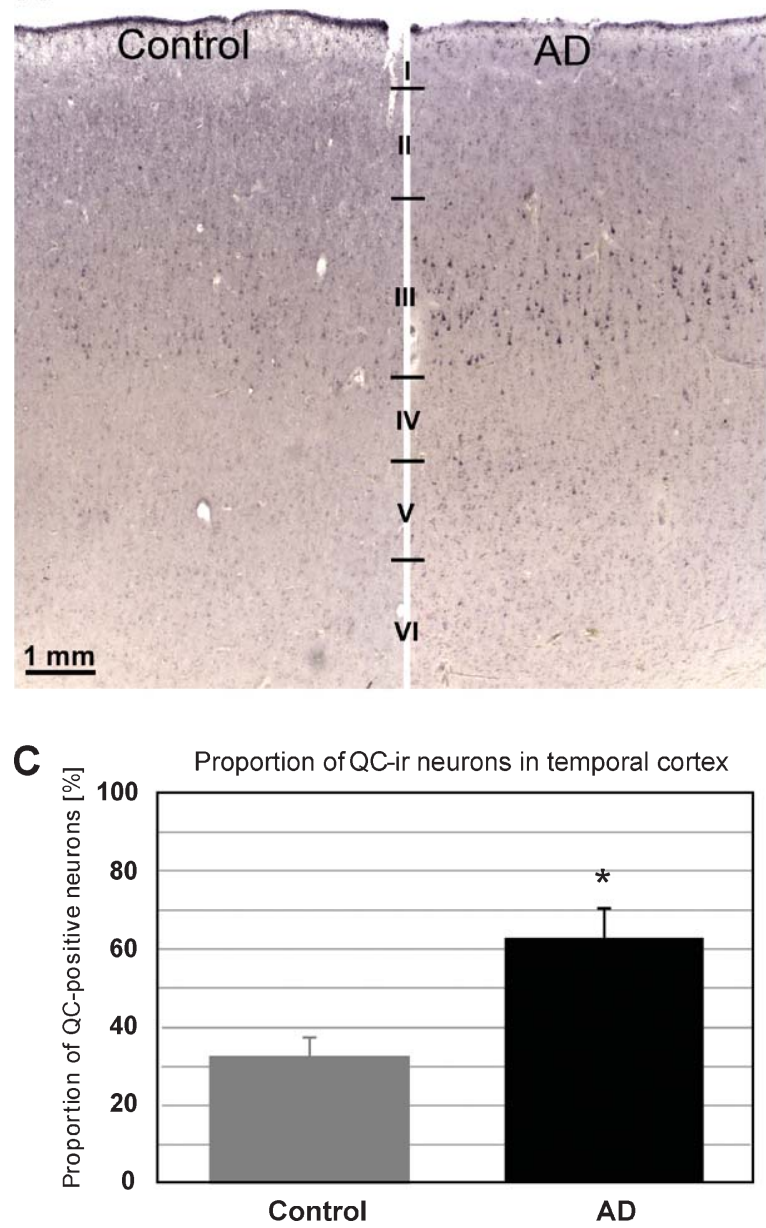

B

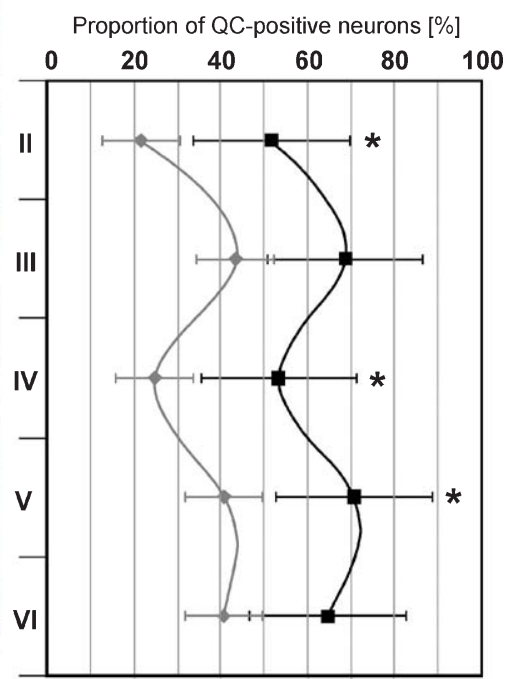
Fig. 2. Density of QC-immunoreactive neurons in human temporal cortex. A) The typical staining pattern for QC in postmortem human
temporal cortex of a control case and an AD case is shown. Note the strong QC immunoreactivity in layer III. B) The laminar distribution of QC immunoreactive neurons is given as per cent of the total neuron number quantified by Nissl staining. The highest density of QC-immunoreactive neurons was detected in layers III and V of control and AD cases with a 20 to $30 \%$ higher frequency across all layers in AD. C) Quantification of the percentage of QC-immunoreactive neurons in control and AD cases across the cortical thickness from layer II to VI. The percentage of QC-immunoreactive neurons is twice as high in $\mathrm{AD}$ as compared to the age-matched control group. $* p<0.0001$; Data are mean values $\pm \mathrm{SD}$; Control: $n=6$; AD: $n=6$.

evident. Although all antibodies labeled the same neuronal populations and revealed a similar subcellular QC distribution, there were considerable differences in the signal to background ratio, with A01 showing the best staining characteristics (Fig. 1). Therefore, this antibody was used for subsequent analyses of QC expression in human control and AD brains.

\section{QC expression in temporal cortex}

In the temporal cortex, a defined laminar distribution of QC immunoreactivity was observed (Fig. 2A). In control cases, approximately 20 to $25 \%$ of neurons in layers II and IV displayed QC immunoreactivity, whereas 40 to $45 \%$ of neurons in layers III, V, and VI were found to be QC-immunoreactive (Fig. 2B). In $\mathrm{AD}$, a similar laminar profile of QC immunoreactivity was detected but the proportion of QC-immunoreactive neurons was 20 to $30 \%$ higher in all cortical layers compared to controls (Fig. 2A, B). This increase was statistically significant in layers II, IV, and V $(p<0.05)$. Quantification of QC immunoreactive neurons over the whole cortical depth revealed a proportion of $31.5 \pm 5.0 \%$ QC-immunoreactive neurons in control brains and of $61.7 \pm 7.8 \%$ in $\mathrm{AD}$ brains (Fig. 2C; $p<0.0001$ ).

As stated above, the QC staining intensity varied considerably between individual neurons. To take into 
A

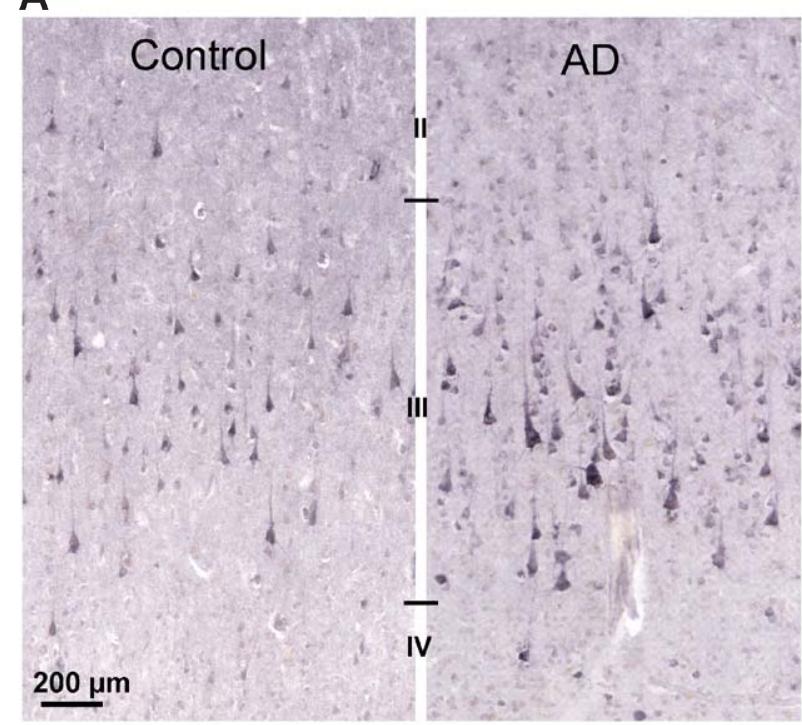

B Proportion of strongly

QC-positive neurons [\%]

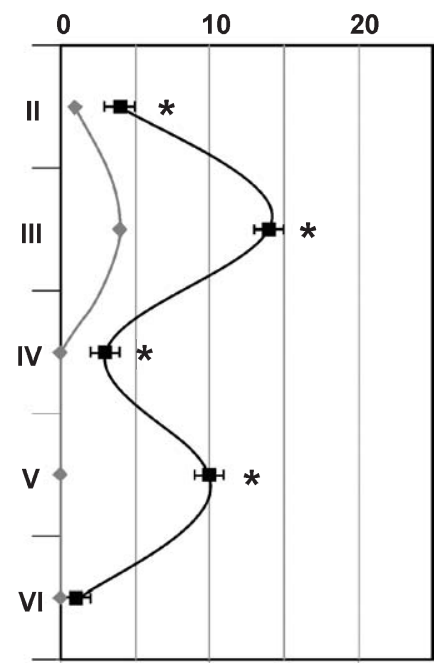

C Strength of QC-ir in temporal cortex

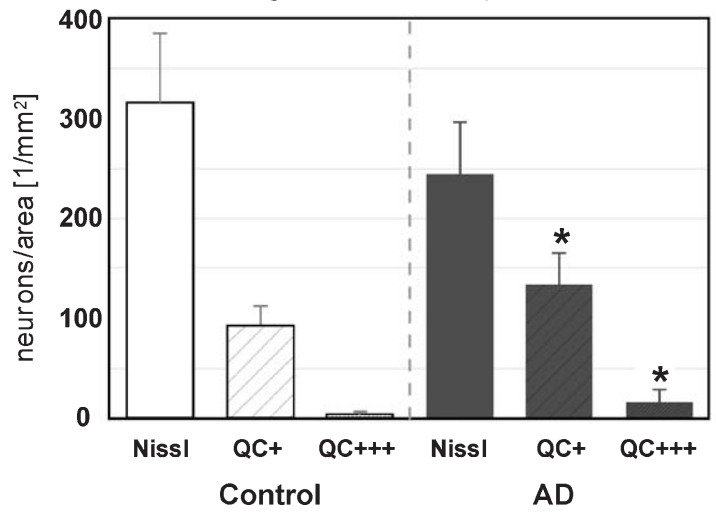

Fig. 3. Strength of the QC immunoreactivity in temporal cortex neurons. A) The immunohistochemical labeling of QC reveals remarkable differences in the staining intensity of individual neurons between control and AD cases. B) Quantification of strongly QC-immunoreactive neurons demonstrates the presence of a minor proportion of such neurons only in cortical layer III of control cases, but in all cortical layers of AD cases. The highest proportion of strongly QC-immunoreactive neurons in AD was detected in layers III and V. C) Quantification of strongly and moderately QC-immunoreactive neurons identifies statistically significant increases in the proportion of both groups of QC neurons in AD. $* p<0.05$; Data are mean values $\pm \mathrm{SD}$; Control: $n=6$; AD: $n=6$.

account this variation, a second analysis differentiating between strongly and moderately QC-immunoreactive neurons in temporal cortex was performed (Fig. 3). In controls, $93 \pm 20$ neurons $/ \mathrm{mm}^{2}$ displayed a moderate and $3 \pm 3$ neurons $/ \mathrm{mm}^{2}$ showed a strong QC immunoreactivity (Fig. 3C). In AD temporal cortex, the number of both moderately (133 \pm 32$)$ and strongly $(16 \pm 12)$ QC immunoreactive neurons per $\mathrm{mm}^{2}$ was significantly higher than in controls (Fig. 3C; $p<0.05$ ). Neurons with strong QC immunoreactivity were exclusively found in layer III of control and in layers III and $\mathrm{V}$ as well as to a lesser extent in layers II and IV of AD temporal cortex (Fig. 3B). In all cortical layers with strongly QC-immunoreactive neurons their proportion was significantly higher in AD than in control brains (Fig. 3B; $p<0.01$ ).

\section{QC expression in entorhinal cortex}

We further compared the QC expression in temporal cortex with the one of entorhinal cortex, which is earlier and more severely affected in the course of AD. In contrast to temporal cortex, entorhinal cortex has a different morphology and layering. In the entorhinal cortex of control cases, more than $80 \%$ of neurons displayed QC immunoreactivity, with the strongest 
A

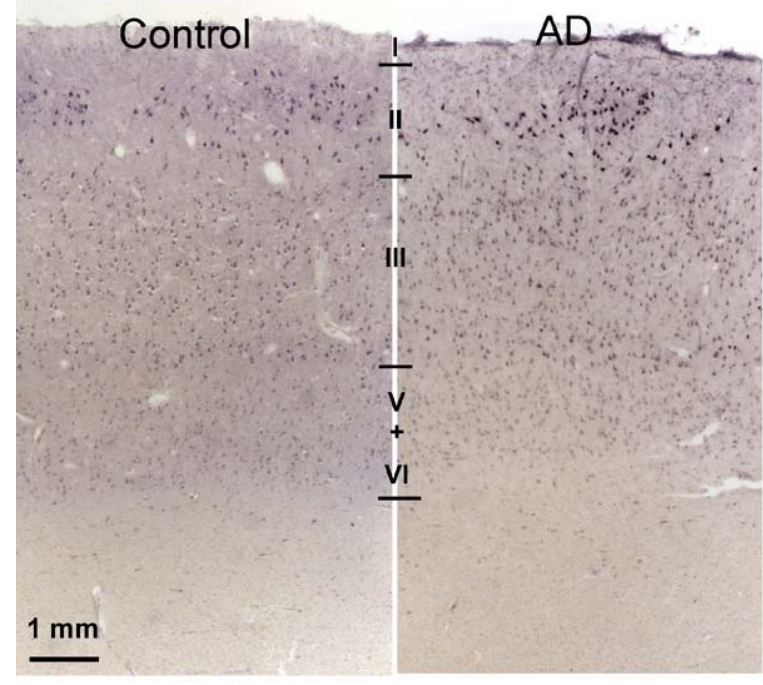

C Proportion ofQC-ir neurons in entorhinal cortex
B

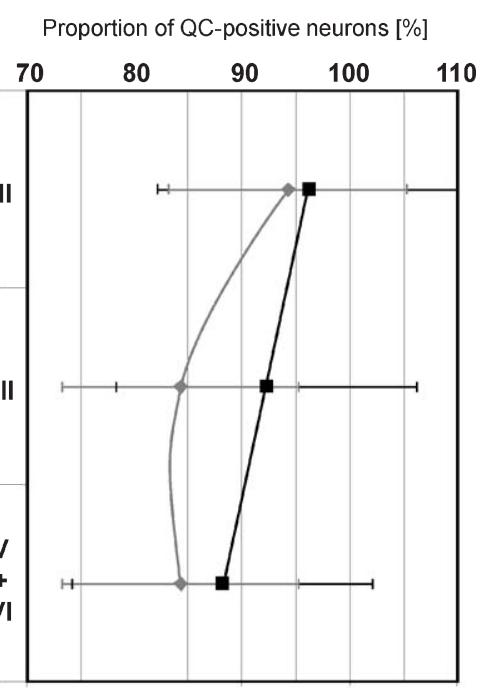

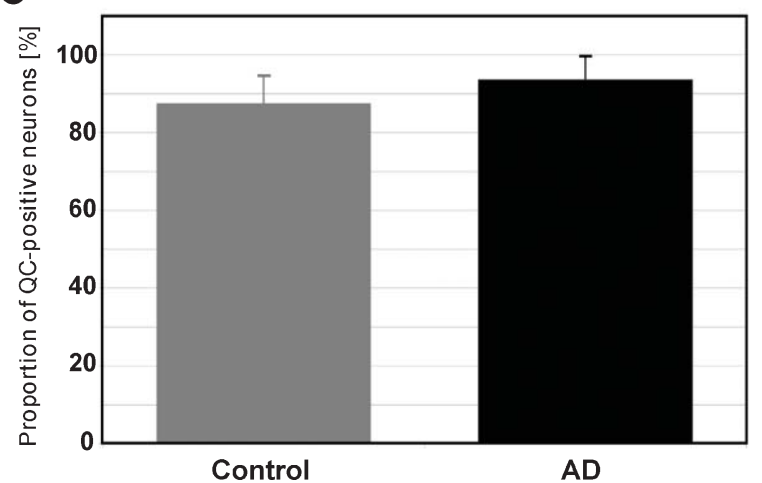

Fig. 4. Density of QC-immunoreactive neurons in human entorhinal cortex. A) A representative staining pattern for QC in postmortem human entorhinal cortex of a control case and an AD case is shown. Note the strong QC immunoreactivity in the islands of layer II and in layer III of the entorhinal cortex. B) The laminar distribution of QC immunoreactive neurons is given as per cent of the total neuron number quantified by Nissl staining. The highest density of QC-immunoreactive neurons was detected in layer II with a gradient toward a lower proportion of QC-immunoreactive neurons in deeper cortical layers. Already in the control group, 85 to $95 \%$ of the neurons expressed QC. There was no statistically significant increase in the density of QC-immunoreactive neurons in any of the entorhinal cortex layers. C) Quantification of the percentage of QC-immunoreactive neurons in control and AD cases revealed no differences between the control and the AD group across the cortical thickness from layer II to VI. Data are mean values \pm SD; Control: $n=6$; AD: $n=6$.

labeling being present in neurons of layer II islands (Fig. 4A, B). In AD entorhinal cortex, a similar staining pattern with approximately $90 \%$ QC-immunoreactive neurons and robust labeling of layer II islands was observed (Fig. 4A, B, C). There was no statistically significant increase in the proportion of QC-positive neurons in $\mathrm{AD}$ entorhinal cortex compared to controls (Fig. 4C).

However, when considering the QC staining intensity of individual neurons, there was a statistically significant increase in the number of strongly QCimmunoreactive neurons in $\mathrm{AD}$ entorhinal cortex $\left(80 \pm 42 / \mathrm{mm}^{2}\right)$ compared to controls $\left(40 \pm 40 / \mathrm{mm}^{2}\right)$
(Fig. 5; $p<0.05$ ). This increase in strongly QCimmunoreactive neurons in $\mathrm{AD}$ was for the most part located in layer III (Fig. 5B) and accompanied by a statistically non-significant decrease in the number of moderately QC-immunoreactive neurons in $\mathrm{AD}\left(140 \pm 45 / \mathrm{mm}^{2}\right)$ compared to controls $\left(179 \pm 72 / \mathrm{mm}^{2}\right)$ (Fig. 5C).

\section{Co-localization of $Q C$ with $p G l u-A \beta$ deposits}

Next, we were interested to reveal whether there is a spatial correlation between QC-immunoreactive neurons and pGlu-A $\beta$ deposits in $\mathrm{AD}$ cortex. In Fig. 6, 
A
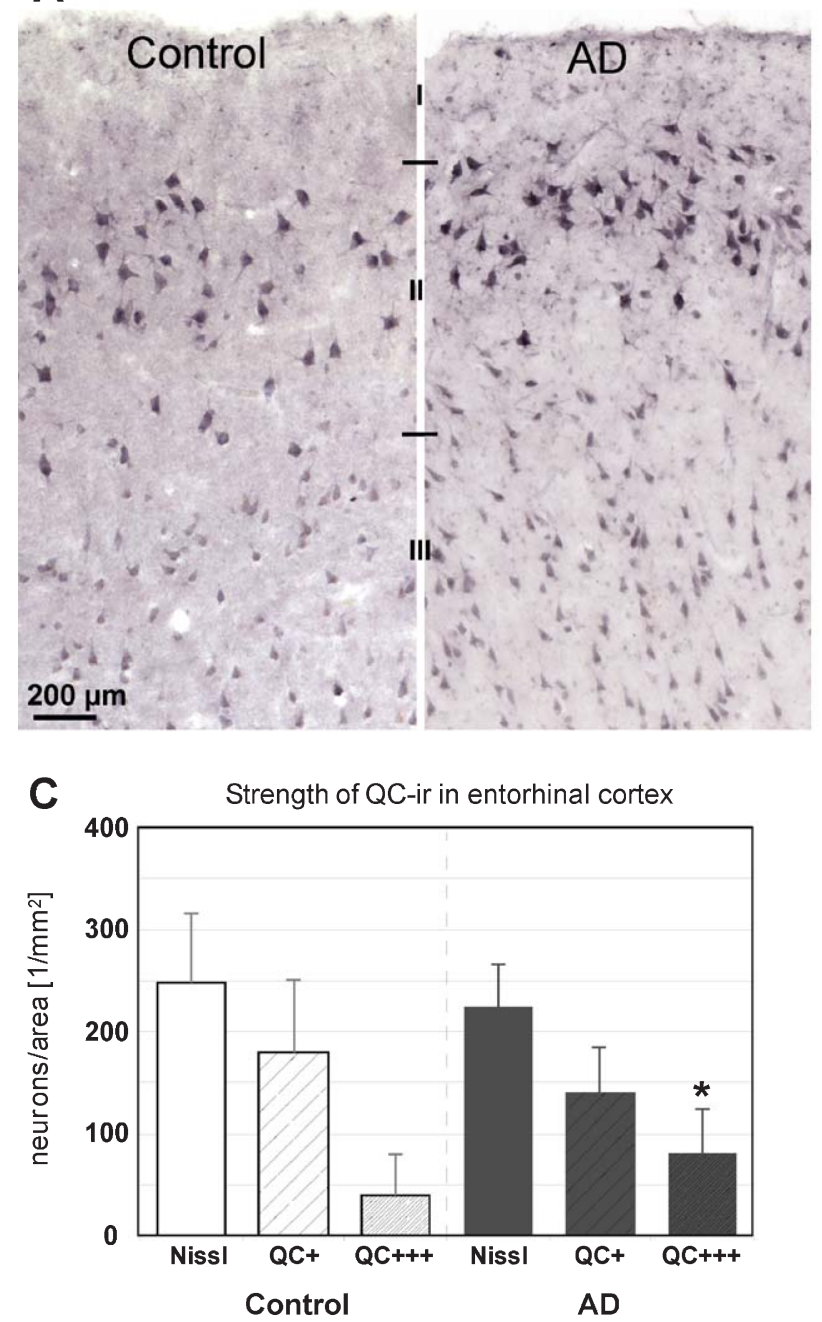

B Proportion of strongly

QC-positive neurons [\%]

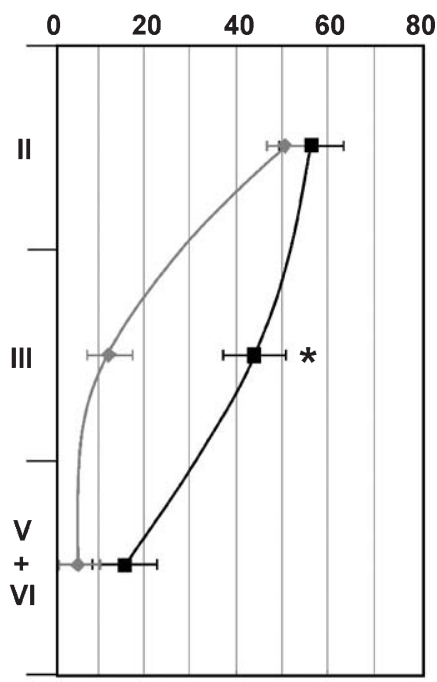

Fig 5. Strength of the QC immunoreactivity in entorhinal cortex neurons. A) The immunohistochemical labeling of QC reveals differences in the staining intensity of individual neurons between control and AD cases. B) Quantification of strongly QC-immunoreactive neurons demonstrates the presence of such neurons in cortical layer II and to a lesser extent in layers III, V and VI of control cases. In AD cases, there is a higher density of strongly QC-immunoreactive neurons in layer III. C) Quantification of strongly and moderately QC-immunoreactive neurons revealed a statistically significant increase in the proportion of strongly QC-immunoreactive neurons in $\mathrm{AD}$, but a statistically non-significant reduction in the proportion of moderately QC-immunoreactive neurons. ${ }^{*} p<0.05$; Data are mean values \pm SD; Control: $n=6$; AD: $n=6$.

an overview of Nissl staining, QC immunohistochemistry, and double labeling for QC (black) and pGlu-A $\beta$ (brown) are shown throughout the entire depth of the temporal cortex. Both QC-immunoreactive neurons and pGlu-A $\beta$ deposits appear to be enriched in layers III and V. However, pGlu-A $\beta$ deposits are also present in layers II and VI, which only harbor a low number of QC immunoreactive neurons. In the high magnification insets on the right panel, examples of a close association of QC-immunoreactive neurons with pGlu-A $\beta$ deposits (middle, bottom) and a lack of such an association (top) are shown. This is consistent with observations made in the hippocampal formation where the appearance of $\mathrm{pGlu}-\mathrm{A} \beta$ deposits in layers devoid of QC-immunoreactive cell bodies, but enriched with QC immunoreactive afferents from entorhinal cortex, was demonstrated [36].

\section{Quantification of QC $m R N A$ and enzymatic activity and ( $p G l u)-A \beta$ in $A D$}

In the second set of human brain tissues, quantitative biochemical analyses were performed with the aims (i) to validate a role of $\mathrm{QC}$ in $\mathrm{pGlu}-\mathrm{A} \beta$ formation in human brain and (ii) to correlate biochemical alterations such as expression of QC and pGlu-A $\beta$ formation with the 


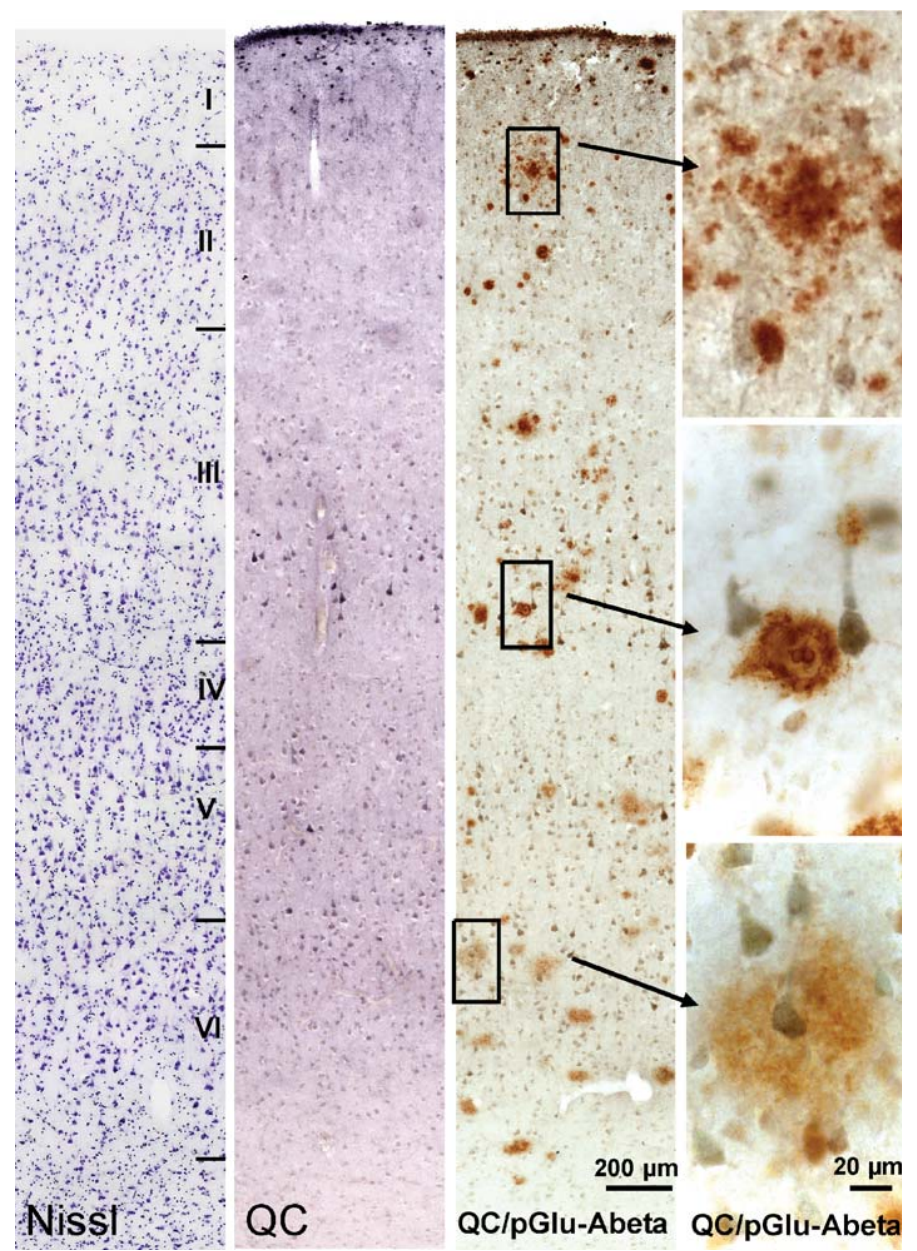

Fig. 6. Spatial association between QC-immunoreactive neurons and pGlu-A $\beta$ deposits. Temporal cortex layers were identified in Nissl-stained brain sections (left). The labeling of QC-immunoreactive neurons (second image from left) demonstrates the highest density of QC in pyramidal neurons in layers III and V. The pGlu-A $\beta$ deposits (brown) were detected in these cortical layers but also layers with a lower abundance of QC-immunoreactive neurons (black) in double labelings (second image from right). In the high magnification images (right), examples of an association between QC-immunoreactive neurons and pGlu-A $\beta$ deposits (bottom, middle) and of a lack of such an association (top) are shown.

test results of MMSE. To address this issue, pathologically and clinically well-characterized brain samples with a short postmortem interval were used (Table 1). In this set of experiments we focused on temporal cortex because entorhinal cortex already showed very high QC expression in controls and no significant increase at the end stage of AD. By using qRT-PCR, an increase in QC mRNA levels by $88.7 \pm 42.6 \%$ in AD temporal cortex compared to controls was detected (Fig. 7A; $p<0.05$ ). There was also a tendency toward increased enzymatic QC activity in AD, which failed to reach statistical significance (Fig. 7A; increase by $31.6 \pm 35.1 \% ; p>0.05)$.

Consistent with our previous observations [30], this $\mathrm{AD}$ cohort also displayed significantly higher pGlu-A $\beta$ (25-fold) and $A \beta_{x-42}$ (70-fold) concen- trations compared to the control cases (Fig. 7B; $p<0.0001)$.

\section{Correlation of $Q C \mathrm{mRNA}$ levels with $p G l u-A \beta$ and MMSE}

In order to validate a role of $\mathrm{QC}$ in $\mathrm{pGlu}-\mathrm{A} \beta$ formation of human brain and in cognitive decline in $\mathrm{AD}$, a series of correlation analyses comparing biochemical and clinical parameters from individual control and AD cases was performed.

Firstly, in order to corroborate the role of QC in pGlu-A $\beta$ formation in human brain, the individual QC mRNA levels were plotted versus pGlu-A $\beta$ and unmodified $A \beta$ concentrations. There was a fairly good correlation between QC mRNA and pGlu-A $\beta$ 

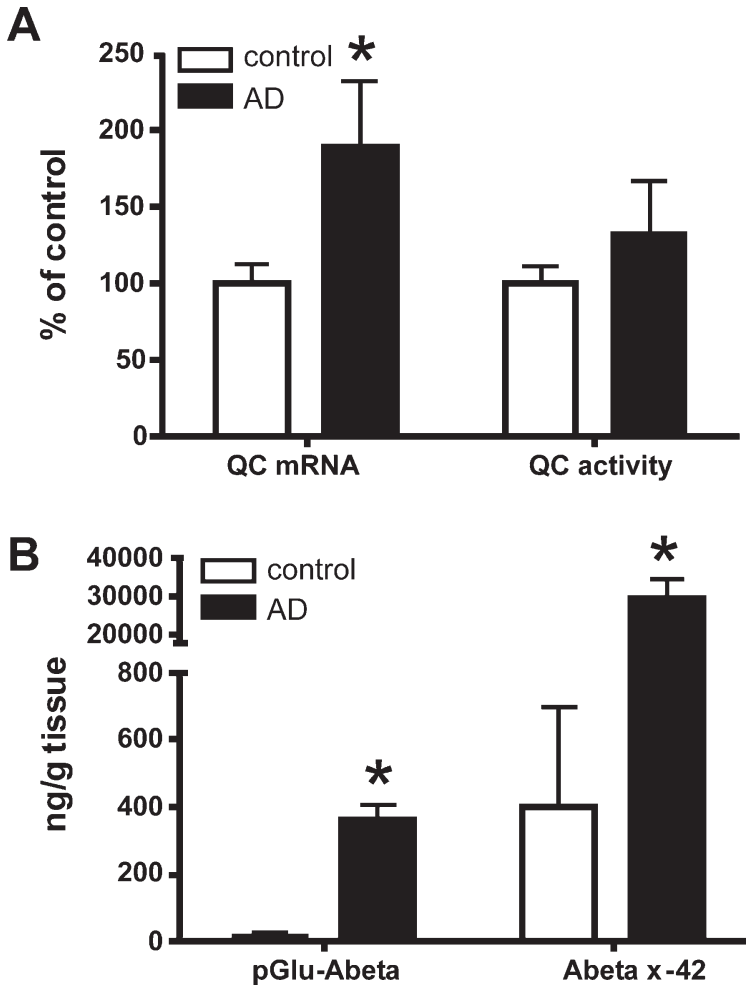

Fig. 7. Alterations in $\mathrm{QC}$ expression, $\mathrm{A} \beta$, and $\mathrm{pGlu}-\mathrm{A} \beta$ peptide concentrations in AD. A) The QC mRNA levels as well as QC enzymatic activity were quantified in temporal cortex samples from control and $\mathrm{AD}$ cases. While the increase in QC mRNA levels in AD was statistically significant, the higher enzymatic activity was not. B) Quantification of the insoluble pool of pGlu-A $\beta$ and $A \beta_{x-42}$ in control and AD cases. The concentrations of both $A \beta$ peptide species were significantly increases in $\mathrm{AD} .{ }^{*} p<0.05$.

$(r=0.6386 ; p=0.0254 ;$ Fig. 8 A $)$. Such a correlation did not exist between QC mRNA levels and unmodified A $\beta$ peptide concentrations (Fig. 8B), substantiating a role of QC in pGlu-A $\beta$ formation in human brain.

Secondly, another important question we sought to address was a possible correlation between (pGlu)-A $\beta$ load and MMSE. As expected, both higher concentrations of unmodified $\mathrm{A} \beta(r=-0.8263 ; p=0.0009$; Fig. 8D) and of pGlu-A $\beta$ ( $r=-0.8867 ; p=0.0001$; Fig. C) showed strong and statistically highly significant correlations with a decline in MMSE, which was, however, almost one order of magnitude higher for pGlu-A $\beta$ in the $p$ value.

\section{DISCUSSION}

This is the first demonstration of a correlation between the clinical status of elderly human subjects as assessed by MMSE on the one hand and the expression of QCs and the concentration of pGlu$\mathrm{A} \beta$ aggregates on the other hand. The presence of pGlu-A $\beta$ in brains of $A D$ patients is known since the mid-1990s [8, 21], but their generation by QC [26] and their pathogenic profiles [12, 13, 24] have only been discovered in the last decade. Interestingly, both QC and pGlu-A $\beta$ were demonstrated to be enriched in subcortical and hippocampal structures known to be severely affected in $\mathrm{AD}[35,37]$. Because of the high aggregation propensity, the seeding capacity to induce deposition of unmodified $A \beta$ peptides and their neurotoxicity, pGlu-A $\beta$ peptides appear as a novel target for AD therapy. Both, prevention of pGlu-A $\beta$ formation by inhibition of QC [29] and removal of pGlu-A $\beta$ aggregates by immunization [45-47] have been demonstrated to be feasible therapeutic strategies in transgenic mouse models. A currently completed phase I clinical trial demonstrated the safety and efficiency of the QC inhibitor PQ912 in healthy humans [48].

However, there is still a lack of data correlating the clinical status of elderly humans with QC expression levels and pGlu-A $\beta$ deposits in brain. To address this issue, we first analyzed QC expression in two cortical areas differentially affected in AD. Temporal cortex (Area 22) is part of the associative cortex involved in language processing [49] and affected at later stages of the disease, while entorhinal cortex (Area 28) is vital for spatial memory formation and consolidation [50, 51] and one of the earliest and most severely affected brain region in $\mathrm{AD}[4,52]$.

Here, we report a widespread expression of QC by temporal cortex neurons in human control subjects. Given the substrate specificity of QC for peptide hormones and neuropeptides present in hypothalamus and in pituitary gland and the involvement of QC in pathogenic $\mathrm{pGlu}-\mathrm{A} \beta$ formation, this observation was unexpected. Such a high QC expression by cortical neurons of control subjects calls for an investigation of currently unknown physiological QC substrates in cortex. On the other hand, the upregulation of $\mathrm{QC}$ expression in temporal cortex of AD patients is in line with the postulated role for $\mathrm{QC}$ in $\mathrm{AD}$ pathogenesis. Both QC mRNA and protein levels have been already reported to be upregulated at early stages of $\mathrm{AD}$ in neocortex [29], hippocampus [53], and peripheral blood cells [54], and there is evidence for a role of disturbed calcium homeostasis in the regulation of QC expression [53]. The frequent association of QC-immunoreactive neurons with pGlu-A $\beta$ deposits in cortical layers III and V is also supportive for a pathogenic role of QC. 
A

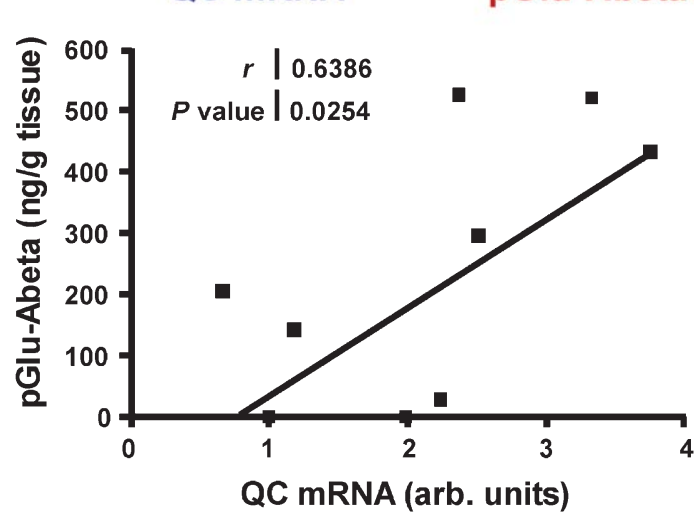

B

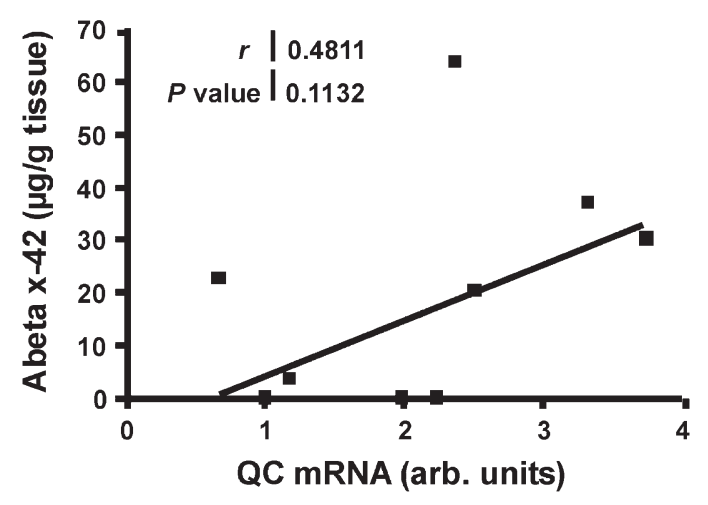

C

pGlu-Abeta versus MMSE

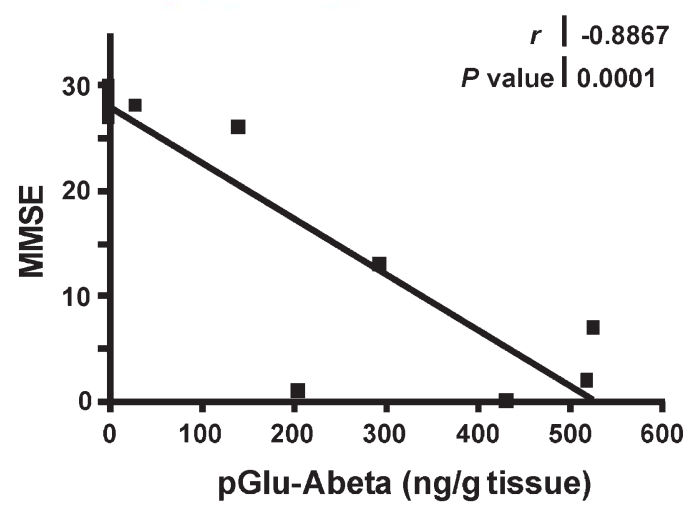

D

Abeta versus MMSE

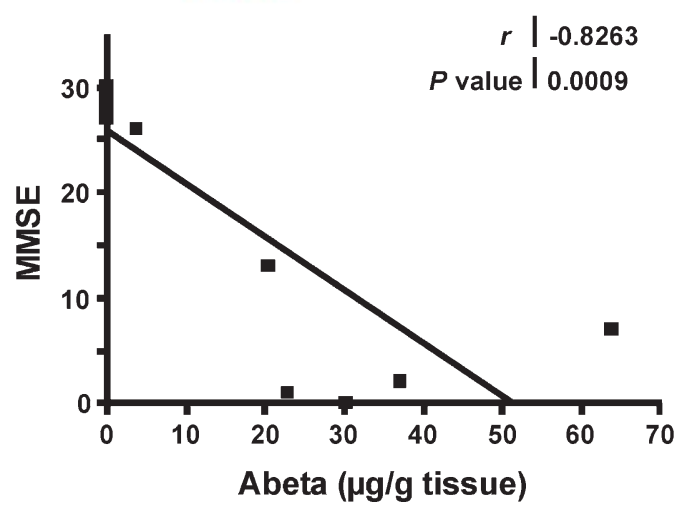

Fig. 8. Correlations between QC mRNA levels, A $\beta$ peptide concentrations, and MMSE. There was a statistically significant correlation between QC mRNA and pGlu-A $\beta$ (A; $r=0.6386 ; p=0.0254)$. Such a correlation did not exist between QC mRNA levels and unmodified A $\beta$ peptide concentrations (B). Both higher concentrations of pGlu-A $\beta(\mathrm{C} ; r=-0.8867 ; p=0.0001)$ and of unmodified A $\beta$ (D; $r=-0.8263 ; p=0.0009)$ showed strong correlations with a decline in MMSE which was one order of magnitude higher for pGlu-A $\beta$. Control: $n=7 ; \mathrm{AD}: n=5$.

There are, however, cortical pGlu-A $\beta$ deposits in layers II and VI that are not obviously associated with QC-immunoreactive neuronal somata. Such a phenomenon has been reported earlier in the hippocampal formation [37] and is most likely due to release of pGlu-A $\beta$ from synaptic terminals of QC-rich neurons. This may include intracortical neurons such as pyramidal neurons and afferents from QC-rich structures like locus coeruleus and nucleus basalis Meynert, which have been reported to express high levels of QC and are affected by pGlu-A $\beta$ pathology in $\mathrm{AD}$ [35]. Such a "seeding from the distance" of $A \beta$ deposits by subcortical neurons has been discussed to contribute to the development of AD pathology [55]. Furthermore, in an $A \beta P P$ transgenic mouse model, the seeding of $A \beta$ deposits in brain structures lacking transgene expression has been shown to occur via synaptic $A \beta$ release from projection neurons [56]. The even higher expression of QC in entorhinal cortex might explain the particularly high vulnerability of this neuronal population in AD.

Since QC expression in temporal cortex displayed higher differences between control and $\mathrm{AD}$ than entorhinal cortex, the former brain region was used for thorough biochemical and clinical analyses. Brain tissue with a very short postmortem delay and a welldocumented clinical status was received from the Bannerhealth Brain Donation Program used for biochemical analyses including qRT-PCR to detect QC mRNA, QC enzymatic activity assays and ELISA to quantify $A \beta$ and pGlu- $A \beta$ concentrations. $Q C$ transcript levels were shown to be elevated in AD temporal cortex, as were insoluble $A \beta$ and pGlu- $A \beta$ concentrations.

For individual cases, biochemical values were correlated with cognitive status as measured by MMSE. Here, a good correlation between QC mRNA levels and the concentration of pGlu-A $\beta$ - but not total $A \beta$ - was 
detected. This provides further evidence for the specificity of QC for pGlu-A $\beta$ formation in human cortex. There were also robust inverse correlations between $\mathrm{A} \beta$ concentrations and MMSE. This is not surprising since both peptide aggregates are characteristic of AD. However, the $p$ value was one order of magnitude higher for the $\mathrm{pGlu}-\mathrm{A} \beta / \mathrm{MMSE}$ correlation than for the $A \beta / M M S E$ correlation. This points toward a specific role of $\mathrm{pGlu}-\mathrm{A} \beta$ in cognitive decline in $\mathrm{AD}$ and underlines the therapeutic potential of targeting pGlu-A $\beta$ by inhibition of QC and by immunization approaches. Since the sample size investigated in the present study is not high and cases with a moderate decline in MMSE are of particular interest for correlation analyses, we are looking forward to additional studies that further strengthen the key findings reported here.

Together, our observations provide evidence for an involvement of $\mathrm{QC}$ in $\mathrm{AD}$ pathogenesis by $\mathrm{QC}$ catalyzed pGlu-A $\beta$ formation which affects cognitive abilities.

\section{ACKNOWLEDGMENTS}

We are grateful to the Banner Sun Health Research Institute Brain Donation Program of Sun City, Arizona for the provision of human brain tissue. The Brain Donation Program is supported by the National Institute on Aging [P30 AG19610 Arizona Alzheimer's Disease Core Center], the Arizona Department of Health Services [contract 211002, Arizona Alzheimer's Research Center], the Arizona Biomedical Research Commission [contracts 4001, 0011, 05-901, and 1001 to the Arizona Parkinson's Disease Consortium], and the Michael J. Fox Foundation for Parkinson's Research. We thank R. Jendrek (Paul Flechsig Institute for Brain Research), K. Schulz and E. Scheel (Probiodrug) for technical assistance. This work was supported by the German Federal Department of Education, Science and Technology, BMBF [grant \#0316033A to HUD and grant \#0316033B to SR]. Further, this work was supported by the German Research Foundation MO 2249/2-1 within the SPP 1608, GRK 1097 "INTERNEURO" to MM, by the COST Action BM1001 "Brain Extracellular Matrix in Health and Disease" to MM, by the Alzheimer Forschungsinitiative e.V. (AFI \#11861 to $\mathrm{MM})$ and by the European Union and the Federal State of Saxony (grant number SAB 100154907) to MM and SR.

Authors' disclosures available online (http://www.jalz.com/disclosures/view.php?id=1956).

\section{REFERENCES}

[1] Maeda J, Zhang MR, Okauchi T, Ji B, Ono M, Hattori S, Kumata K, Iwata N, Saido TC, Trojanowski JQ, Lee VM, Staufenbiel M, Tomiyama T, Mori H, Fukumura T, Suhara $\mathrm{T}$, Higuchi M (2011) In vivo positron emission tomographic imaging of glial responses to amyloid-beta and tau pathologies in mouse models of Alzheimer's disease and related disorders. J Neurosci 31, 4720-4730.

[2] Leung KK, Bartlett JW, Barnes J, Manning EN, Ourselin S, Fox NC; Alzheimer's Disease Neuroimaging Initiative (2013) Cerebral atrophy in mild cognitive impairment and Alzheimer disease: Rates and acceleration. Neurology 80, 648-654.

[3] Schuitemaker A, Kropholler MA, Boellaard R, van der Flier WM, Kloet RW, van der Doef TF, Knol DL, Windhorst AD, Luurtsema G, Barkhof F, Jonker C, Lammertsma AA, Scheltens P, van Berckel BN (2013) Microglial activation in Alzheimer's disease: An (R)-[11C]PK11195 positron emission tomography study. Neurobiol Aging 34, 128-136.

[4] Braak H, Braak E (1991) Neuropathological stageing of Alzheimer-related changes. Acta Neuropathol 81, 239-259.

[5] Mirra SS, Heyman A, McKeel D, Sumi SM, Crain BJ, Brownlee LM, Vogel FS, Hughes JP, van Belle G, Berg L (1991) The Consortium to Establish a Registry for Alzheimer's Disease (CERAD). Part II. Standardization of the neuropathologic assessment of Alzheimer's disease. Neurology 41, 479-486.

[6] Selkoe DJ, Schenk D (2003) Alzheimer's disease: Molecular understanding predicts amyloid based therapeutics. Annu Rev Pharmacol Toxicol 43, 545-584.

[7] Haass C (2004) Take five-BACE and the gamma-secretase quartet conduct Alzheimer's amyloid beta-peptide generation. EMBO J 23, 483-488.

[8] Saido TC, Iwatsubo T, Mann DM, Shimada H, Ihara Y, Kawashima S (1995) Dominant and differential deposition of distinct beta-amyloid peptide species, Abeta N3(pE), in senile plaques. Neuron 14, 457-466.

[9] Saido TC, Yamao H, Iwatsubo T, Kawashima S (1996) Amino- and carboxyl-terminal heterogeneity of beta-amyloid peptides deposited in human brain. Neurosci Lett 215, 173176.

[10] Russo C, Schettini G, Saido TC, Hulette C, Lippa C, Lannfelt L, Ghetti B, Gambetti P, Tabaton M, Teller JK (2000) Presenilin-1 mutations in Alzheimer's disease. Nature 405, 531-532.

[11] Sevalle J, Amoyel A, Robert P, Fournié-Zaluski MC, Roques B, Checler F (2009) Aminopeptidase A contributes to the $\mathrm{N}$-terminal truncation of amyloid beta-peptide. J Neurochem 109, 248-256.

[12] Miravalle L, Calero M, Takao M, Roher AE, Ghetti B, Vidal R (2005) Amino-terminally truncated Abeta peptide species are the main component of cotton wool plaques. Biochemistry 44, 10810-10821.

[13] Piccini A, Russo C, Gliozzi A, Relini A, Vitali A, Borghi R, Giliberto L, Armirotti A, D'Arrigo C, Bachi A, Cattaneo A, Canale C, Torrassa S, Saido TC, Markesbery W, Gambetti P, Tabaton M (2005) Beta-amyloid is different in normal aging and in Alzheimer's disease. J Biol Chem 280, 34186-34192.

[14] Portelius E, Bogdanovic N, Gustavsson MK, Volkmann I, Brinkmalm G, Zetterberg H, Winblad B, Blennow K (2010) Mass spectrometric characterization of brain amyloid beta isoform signatures in familial and sporadic Alzheimer's disease. Acta Neuropathol 120, 185-193.

[15] He W, Barrow CJ (1999) The A beta 3-pyroglutamyl and 11pyroglutamyl peptides found in senile plaque have greater 
beta-sheet forming and aggregation propensities in vitro than full-length A beta. Biochemistry 38, 10871-10877.

[16] Russo C, Violani E, Salis S, Venezia V, Dolcini V, Damonte G, Benatti U, D'Arrigo C, Patrone E, Carlo P, Schettini G (2002) Pyroglutamate-modified amyloid beta-peptides AbetaN3(pE) - strongly affect cultured neuron and astrocyte survival. J Neurochem 82, 1480-1489.

[17] Schilling S, Lauber T, Schaupp M, Manhart S, Scheel E, Böhm G, Demuth HU (2006) On the seeding and oligomerization of pGlu-amyloid peptides (in vitro). Biochemistry 45, 1239312399.

[18] Schlenzig D, Manhart S, Cinar Y, Kleinschmidt M, Hause G, Willbold D, Funke SA, Schilling S, Demuth HU (2009) Pyroglutamate formation influences solubility and amyloidogenicity of amyloid peptides. Biochemistry 48, 7072-7078.

[19] D'Arrigo C, Tabaton M, Perico A (2009) N-terminal truncated pyroglutamyl beta amyloid peptide Abetapy3-42 shows a faster aggregation kinetics than the full-length Abeta1-42. Biopolymers 91, 861-873.

[20] McColl G, Roberts BR, Gunn AP, Perez KA, Tew DJ, Masters CL, Barnham KJ, Cherny RA, Bush AI (2009) The Caenorhabditis elegans A $\beta 1-42$ model of Alzheimer's disease predominantly expresses A $33-42$. J Biol Chem $\mathbf{2 8 4}, 22697$ 22702.

[21] Saido TC (1998) Alzheimer's disease as proteolytic disorders: Anabolism and catabolism of beta-amyloid. Neurobiol Aging 19, S69-S75.

[22] Acero G, Manutcharian K, Vasilevko V, Munguia ME, Govezensky T, Coronas G, Luz-Madrigal A, Cribbs DH, Gevorkian G (2009) Immunodominant epitope and properties of pyroglutamate-modified $\mathrm{A} \beta$-specific antibodies produced in rabbits. J Neuroimmunol 213, 39-46.

[23] Wirths O, Breyhan H, Cynis H, Schilling S, Demuth HU, Bayer TA (2009) Intraneuronal pyroglutamate-Abeta 3-42 triggers neurodegeneration and lethal neurological deficits in a transgenic mouse model. Acta Neuropathol 118, 487-496.

[24] Nussbaum JM, Schilling S, Cynis H, Silva A, Swanson E, Wangsanut T, Tayler K, Wiltgen B, Hatami A, Rönicke R, Reymann K, Hutter-Paier B, Alexandru A, Jagla W, Graubner S, Glabe CG, Demuth HU, Bloom GS (2012) Prion-like behaviour and tau-dependent cytotoxicity of pyroglutamylated amyloid- $\beta$. Nature 485, 651-655.

[25] Maeda J, Ji B, Irie T, Tomiyama T, Maruyama M, Okauchi T, Staufenbiel M, Iwata N, Ono M, Saido TC, Suzuki K, Mori H, Higuchi M, Suhara T (2007) Longitudinal, quantitative assessment of amyloid, neuroinflammation, and anti-amyloid treatment in a living mouse model of Alzheimer's disease enabled by positron emission tomography. $J$ Neurosci $\mathbf{2 7}$, 10957-10968.

[26] Schilling S, Hoffmann T, Manhart S, Hoffmann M, Demuth HU (2004) Glutaminyl cyclases unfold glutamyl cyclase activity under mild acid conditions. FEBS Lett 563, 191-196.

[27] Cynis H, Schilling S, Bodnar M, Hoffmann T, Heiser U, Saido TC, Demuth HU (2006) Inhibition of glutaminyl cyclase alters pyroglutamate formation in mammalian cells. Biochim Biophys Acta 1764, 1618-1625.

[28] Cynis H, Scheel E, Saido TC, Schilling S, Demuth HU (2008) Amyloidogenic processing of amyloid precursor protein: Evidence of a pivotal role of glutaminyl cyclase in generation of pyroglutamate-modified amyloid-beta. Biochemistry 47, 7405-7413.

[29] Schilling S, Zeitschel U, Hoffmann T, Heiser U, Francke M, Kehlen A, Holzer M, Hutter-Paier B, Prokesch M, Windisch M, Jagla W, Schlenzig D, Lindner C, Rudolph T, Reuter G, Cynis H, Montag D, Demuth HU, Roßner S (2008) Glu- taminyl cyclase inhibition attenuates pyroglutamate Abeta and Alzheimer's disease-like pathology. Nature Med 14, 1106-1111.

[30] Schilling S, Appl T, Hoffmann T, Cynis H, Schulz K, Jagla W, Friedrich D, Wermann M, Buchholz M, Heiser U, von Hörsten S, Demuth HU (2008) Inhibition of glutaminyl cyclase prevents $\mathrm{pGlu}-\mathrm{A} \beta$ formation after intracortical/hippocampal microinjection in vivo/in situ. J Neurochem 106, 1225-1236.

[31] Fischer WH, Spiess J (1987) Identification of a mammalian glutaminyl cyclase converting glutaminyl into pyroglutamyl peptides. Proc Natl Acad Sci U S A 84, 3628-3632.

[32] Busby WH, Quackenbush GE, Humm J, Youngblood WW, Kizer JS (1987) An enzyme(s) that converts glutaminylpeptides into pyroglutamyl-peptides. J Biol Chem 262, 8532-8536.

[33] Pohl T, Zimmer M, Mugele K, Spiess J (1991) Primary structure and functional expression of a glutaminyl cyclase. Proc Natl Acad Sci U S A 88, 10059-10063.

[34] Böckers TM, Kreutz MR, Pohl T (1995) Glutaminyl-cyclase expression in the bovine/porcine hypothalamus and pituitary. J Neuroendocrinol 7, 445-453.

[35] Morawski M, Hartlage-Rübsamen M, Jäger C, Waniek A, Schilling S, Schwab C, McGeer P, Arendt T, Demuth HU, Roßner S (2010) Distinct glutaminyl cyclase expression in Edinger-Westphal nucleus, locus coeruleus and nucleus basalis Meynert contributes to pGlu-A $\beta$ pathology in Alzheimer's disease. Acta Neuropathol 120, 195-207.

[36] Hartlage-Rübsamen M, Staffa K, Waniek A, Wermann M, Hoffmann T, Cynis H, Schilling S, Demuth HU, Roßner S (2009) Developmental expression and subcellular localization of glutaminyl cyclase in mouse brain. Int J Dev Neurosci 27, 825-835.

[37] Hartlage-Rübsamen M, Morawski M, Waniek A, Jäger C, Zeitschel U, Koch B, Cynis H, Schilling S, Schliebs R, Demuth HU, Roßner S (2011) Glutaminyl cyclase contributes to the formation of focal and diffuse pyroglutamate (pGlu)$\mathrm{A} \beta$ deposits in hippocampus via distinct cellular mechanisms. Acta Neuropathol 121, 705-719.

[38] Alexandru A, Jagla W, Graubner S, Becker A, Bäuscher C, Kohlmann S, Sedlmeier R, Raber KA, Cynis H, Rönicke R, Reymann KG, Petrasch-Parwez E, Hartlage-Rübsamen M, Waniek A, Roßner S, Schilling S, Osmand AP, Demuth HU, von Hörsten S (2011) Selective hippocampal neurodegeneration in transgenic mice expressing small amounts of truncated $\mathrm{A} \beta$ is induced by pyroglutamate- $\mathrm{A} \beta$ formation. J Neurosci $\mathbf{3 1}$, 12790-12801.

[39] Jawhar S, Wirths O, Schilling S, Graubner S, Demuth HU, Bayer TA (2011) Overexpression of glutaminyl cyclase, the enzyme responsible for pyroglutamate Abeta formation, induces behavioral deficits, and glutaminyl cyclase knockout rescues the behavioral phenotype in 5XFAD mice. $J$ Biol Chem 286, 4454-4460.

[40] Beach TG, Sue LI, Walker DG, Roher AE, Lue L, Vedders L, Connor DJ, Sabbagh MN, Rogers J (2008) The Sun Health Research Institute Brain Donation Program: Description and experience, 1987-2007. Cell Tissue Bank 9, 229-245.

[41] Mai JK, Assheuer J, Paxinos G (2004) Atlas of the human brain. Academic Press, San Diego.

[42] Wirths O, Bethge T, Marcello A, Harmeier A, Jawhar S, Lucassen PJ, Multhaup G, Brody DL, Esparza T, Ingelsson M, Kalimo H, Lannfelt L, Bayer TA (2010) Pyroglutamate Abeta pathology in APP/PS1KI mice, sporadic and familial Alzheimer's disease cases. J Neural Transm 117, 85-96. 
[43] Konigsmark BW (1970) Methods for the counting of neurons. In Contemporary Research Methods in Neuroanatomy, Nauta WHJ, Ebbesson SOE, eds. Springer, Berlin, pp. 315-380.

[44] Andersen CL, Ledet-Jensen J, Ørntoft T (2004) Normalization of real-time quantitative RT-PCR data: A model based variance estimation approach to identify genes suited for normalization - applied to bladder- and colon-cancer data-sets. Cancer Res 64, 5245-5250.

[45] Wirths O, Erck C, Martens H, Harmeier A, Geumann C, Jawhar S, Kumar S, Multhaup G, Walter J, Ingelsson M, Degerman-Gunnarsson M, Kalimo H, Huitinga I, Lannfelt L, Bayer TA (2010) Identification of low molecular weight pyroglutamate Abeta oligomers in Alzheimer disease: A novel tool for therapy and diagnosis. J Biol Chem 285, 4151741524.

[46] Frost JL, Liu B, Kleinschmidt M, Schilling S, Demuth HU, Lemere CA (2012) Passive immunization against pyroglutamate- 3 amyloid- $\beta$ reduces plaque burden in Alzheimer-like transgenic mice: A pilot study. Neurodegener Dis 10, 265-270.

[47] Demattos RB, Lu J, Tang Y, Racke MM, Delong CA, Tzaferis JA, Hole JT, Forster BM, McDonnell PC, Liu F, Kinley RD, Jordan WH, Hutton ML (2012) A plaque-specific antibody clears existing $\beta$-amyloid plaques in Alzheimer's disease mice. Neuron 76, 908-920.

[48] Weber F, Lues I, Meyer A, Hoffmann T, Pokorny R, Lopez L, Demuth HU, Glund K (2013) A phase 1 study assessing safety, pharmacokinetics and pharmacodynamics of PQ912, the first glutaminyl cyclase (QC) inhibitor to treat AD. 11th Conference on Alzheimer's disease and Parkinson's disease. Florence, March 6-10, 2013; Abstract 1453.
[49] Saygin AP, Dick F, Wilson SM, Dronkers NF, Bates E (2003) Neural resources for processing language and environmental sounds: Evidence from aphasia. Brain 126, 928-945.

[50] Jacobs J, Kahana MJ, Ekstrom AD, Mollison MV, Fried I (2010) A sense of direction in human entorhinal cortex. Proc Natl Acad Sci U S A 107, 6487-6492.

[51] Suthana N, Haneef Z, Stern J, Mukamel R, Behnke E, Knowlton B, Fried I (2012) Memory enhancement and deep-brain stimulation of the entorhinal Area. $N$ Engl J Med 366, 501510.

[52] Serrano-Pozo A, Frosch MP, Masliah E, Hyman BT (2011) Neuropathological alterations in Alzheimer's disease. Cold Spring Harb Perspect Med 1, a006189.

[53] De Kimpe L, Bennis A, Zwart R, van Haastert ES, Hoozemans JJ, Scheper W (2012) Disturbed $\mathrm{Ca}^{+}$homeostasis increases glutaminyl cyclase expression; connecting two early pathogenic events in Alzheimer's disease in vitro. PLOS One 7, e44674.

[54] Valenti MT, Bolognin S, Zanatta C, Donatelli L, Innamorati G, Pampanin M, Zanusso G, Zatta P, Dalle Carbonare L (2013) Increased glutaminyl cyclase expression in peripheral blood of Alzheimer's disease patients. J Alzheimers Dis 34, 263-271.

[55] Muresan Z, Muresan V (2008) Seeding neuritic plaques from the distance: A possible role for brainstem neurons in the development of Alzheimer's disease. Neurodegener Dis $\mathbf{5}$, 250-253.

[56] Christensen DZ, Kraus SL, Flohr A, Cotel MC, Wirths O, Bayer TA (2008) Transient intraneuronal A $\beta$ rather than extracellular plaque pathology correlates with neuron loss in the frontal cortex of APP/PS1 mice. Acta Neuropathol 116, 647655 . 